\title{
Viral Hepatitis in India: A Report from Delhi
}

\author{
Mohammad Irshad (Corresponding author) \\ Clinical Biochemistry Division, Department of Laboratory Medicine \\ All India Institute of Medical Sciences, New Delhi-110029, India \\ Tel: 91-011-2659-4981_E-mail: drirshad54@yahoo.com
}

Shiwani Singh \& Mohammad Ahmad Ansari

Clinical Biochemistry Division, Department of Laboratory Medicine

All India Institute of Medical Sciences, New Delhi-110029, India

Yogendra Kumar Joshi

Department of Gastroenterology and Human Nutrition

All India Institute of Medical Sciences, New Delhi-110029, India

\begin{abstract}
Present study reports the etiological spectrum of viral hepatitis in different types of liver diseases in north India. Sera from a total number of 370 adult patients belonging to various liver diseases were analysed for different markers of hepatitis virus A, B, C, D and E infections. These sera were also tested to detect Torque Teno Virus (TTV) infection in them. The results of analysis show hepatitis A virus (HAV) infection to be rare with hepatitis $\mathrm{B}$ virus (HBV) and hepatitis $\mathrm{C}$ virus $(\mathrm{HCV})$ as the predominant cause of acute and chronic liver diseases. Similarly, hepatitis E virus (HEV) infection is quite common in acute viral hepatitis (AVH) and fulminant hepatic failure (FHF) patients. Hepatitis D virus (HDV) infection could not be detected in these patients. TTV-DNA was detected in high proportions in all the disease groups. All types of viral hepatitis in these liver diseases have been discussed for various aspects.
\end{abstract}

Keywords: Hepatitis, HBV, HCV, TTV, Infection, DNA, Epidemiology, CLD

\section{Introduction}

Viral hepatitis is a major public health problem throughout the world. This is a serious problem in India also and has been reported from all parts of this country. Moreover, all types of viruses, already characterized and identified as the causative agent of viral hepatitis infect Indian populations. Our earlier reports (Irshad M, 1994) clearly demonstrate that all these hepatitis viruses reside in this country, usually in endemic forms. Hepatitis A virus (HAV) is an RNA virus that infects mainly children and develops protective immunity till the adult age is attained (Tandon BN, 1984). It is not detected commonly in adult. HAV infection remains either asymptomatic or resolves with mild symptoms without development of chronic disease. However, once it occurs as a co-infection with other viruses, it may develop serious disease (Tandon BN, 1984).

Hepatitis B virus (HBV) is a double stranded DNA virus, and an established cause of acute and chronic liver disease with its major role in causation of hepatocellular carcinoma ( $\mathrm{Si}$ Ahmed SN, 2009). It is a blood transmitted virus and spreads in the community both via vertical as well as horizontal modes. Although in majority of cases, it resolves with time, however, nearly one tenth of infected populations develop chronic infection that may remain asymptomatic for years.

Similarly hepatitis C virus (HCV), which was earlier known as blood borne non-A, non-B hepatitis virus, was characterized in 1989 (Choo, Q. L., 1989; Bradley DW., 1992) and since then, has been reported to be an important cause of chronic liver disease and HCC throughout the world. Hepatitis D virus, an incomplete RNA virus requiring presence of $\mathrm{HBsAg}$ for its replication and sustenance in circulation, has been reported from various countries with its significant presence in certain specific pockets of the world (Farci P, 1986). Hepatitis E virus, a component of non-A, non-B hepatitis viruses and earlier known as orally transmitted or water borne non-A, non-B infection, has also been reported to be prevalent in different countries(Irshad M., 1999; 
Crawczynski K, 1993), of course, in different proportions. Although, viral hepatitis is assumed to be caused by several other viruses including hepatitis G virus (Linnen J, 1996), EBV and TTV etc.(Irshad M, 2006), however, their role in causation of liver diseases and its severity is not fully established. Besides, there is still a group of viruses that cause hepatitis but have not yet been identified and termed as non-A-E hepatitis viruses.

Present report describes the etiological spectrum of viral hepatitis in various forms of liver diseases to update our knowledge about their relative status in reference to the new markers available to diagnose these infections using more accurate and sensitive techniques. This study in a large population of patients belonging to each disease group, gives out a clear picture on the status of viral hepatitis in this country. These informations are also supposed to help in the clinical management of diseases and predict prognostic significance of the ongoing infection.

\section{Material \& Methods}

\subsection{Patients and blood samples}

Three hundred and seventy patients of both sexes and in adult age group were included in the present study. Seventy six patients (age range: 21-48years) were diagnosed as having acute viral hepatitis (AVH); 102 patients (age range: $19-48$ years) with chronic viral hepatitis $(\mathrm{CVH}), 96$ patients (age range: $34-57$ years) were found to have cirrhosis of the liver, 54 patients (age range: 28-46) with fulminant hepatic failure (FHF) and 42 patients (age range: 47-68 years) with hepatocellular carcinoma (HCC). None of the subjects belongs to more than one disease group. Each group has separate patients' population. All these patients attended either outpatient department or were admitted to the liver unit of All India Institute of Medical Sciences, New Delhi, from October 2006 to March 2009. They were evaluated clinically and biochemically and their sera were tested for hepatitis viral markers. The diagnosis of different types of liver diseases was based on accepted clinical, biochemical and histological criteria as outlined elsewhere (Tandon BN, 1986). All procedures including selection of patients were followed as per guidelines of ethical regulations at this institute. AVH was diagnosed when patients exhibited overt jaundice and / or increased alanine aminotransferase levels (at least 3 times above the normal value) documented at least twice at a 1-week interval without any history of pre-existing liver disease. None of the patients had a past history of alcohol intake or using any drug. We also could not find any clinical or serological evidence of autoimmune diseases or biliary infection in these patients. The patients with $\mathrm{CVH}$ and cirrhosis of liver were diagnosed by histopathological criteria laid down by international study group on chronic hepatitis (International Study Group on chronic hepatitis, 1977). All these CVH patients had persistent elevation of transaminases level (at least 2 times the upper limit of normal range) for more than six months, histologic evidence of chronic hepatitis on liver biopsy at the beginning of follow-up and exclusion of alcohol abuse and other possible causes of chronic liver diseases. Cirrhosis patients were not found to have history of chronic alcohol intake. Fulminant hepatic failure was diagnosed if the patients developed hepatic encephalopathy within 4 weeks of the onset of acute hepatitis as outlined elsewhere (Tandon BN, 1986). Hundred age and sex matched healthy subjects were used as controls.

From each of the above patients, $6-10 \mathrm{ml}$ of venous blood was drawn and aliquoted in plain tubes without anticoagulant. Serum was separated after centrifugation and then stored at $-70^{\circ} \mathrm{C}$ until further analyzed. Repeated freezing and thawing of serum was avoided as far as possible. These sera samples were used to analyze various hepatitis markers, liver function tests and hepatitis $\mathrm{C}$ virus (HCV) core protein.

\subsection{Hepatitis viral markers}

Sera were investigated for hepatitis B surface antigen ( $\mathrm{HBsAg}$ ) and IgM antibodies to hepatitis A virus (IgM anti-HAV), hepatitis B core antigen (IgM anti-HBc), hepatitis D virus (IgM anti-HDV) and hepatitis E virus (IgM anti-HEV). Similarly, all these sera were also tested for total antibodies against hepatitis $\mathrm{C}$ virus (anti-HCV). The serological analysis was done using enzyme immunoassay kits of high sensitivity and specificity obtained from internationally known firms. Kits for HBsAg, IgM anti-HBc and IgM anti-HAV were purchased from Abbot Laboratories, USA. Anti-HCV was tested using highly sensitive third generation ELISA kit from Ortho Diagnostics. This anti-HCV kit used peptides versus core, NS3, NS4 and NS5 regions of HCV genome, as antigen to coat the ELISA plate. IgM antibody to hepatitis D virus (HDV) was tested using an enzyme immunoassay kit from Wellcome. Similarly, IgM anti-HEV was tested using third generation ELISA kit from Genelabs and Diagnostics, Biotechnology, Singapore.

\subsection{HCV Core Ag Assay}

Sera samples were assayed for HCV core protein according to the manufacturer's instructions using EIA kit from Ortho Diagnostics, UK. One hundred $\mu \mathrm{L}$ of samples and controls were mixed with $100 \mu \mathrm{L}$ of a 
pretreatment buffer. For the ELISA reaction, $200 \mu \mathrm{L}$ of pretreated samples and controls were incubated for 95 minutes at $37^{\circ} \mathrm{C}$ with continuous shaking in the antibody-coated wells of a microtiter plate. The plates were washed and incubated for 30 minutes at $37^{\circ} \mathrm{C}$ with $200 \mu \mathrm{L}$ of conjugate, washed again, and incubated for 30 minutes at $37^{\circ} \mathrm{C}$ with $200 \mu \mathrm{L}$ of substrate. The optical densities (ODs) were read in a spectrophotometer at 490 $\mathrm{nm}$ using a $620 \mathrm{~nm}$ reference. The samples and controls were tested in duplicate and the mean OD of each duplicate testing was used. The samples that exhibited more than $25 \%$ variation between the two ODs were considered invalid and retested. As recommended by the manufacturer, the lower detection cutoff was established for each run and corresponded to the mean OD of the 2 negative controls plus 0.040 . A sample was considered positive only when the mean OD was higher than the cutoff OD of the corresponding run.

\subsection{Detection of HCV-RNA by RT-PCR}

HCV-RNA was isolated from 100- $\mu$ l serum or plasma using High Pure Isolation kit from Roche, Germany, according to the method given in instructions manual. It was immediately used in reverse transcriptase (RT) PCR experiments or stored at $-70^{\circ} \mathrm{C}$. Five $\mu \mathrm{l}$ of the isolated RNA was applied to reverse transcription and nested PCR with primers located in the highly conserved $5^{\prime}$ noncoding region (5 ${ }^{`} \mathrm{NCR}$ ) using BIOHCV kit (B\&M Labs., Madrid, Spain). The reverse transcription mixture was incubated for $1 \mathrm{~min}$ at $85^{\circ} \mathrm{C}$, followed by $30 \mathrm{~min}$ at $60^{\circ} \mathrm{C}$. First PCR was performed in whole content after adding $40 \mu \mathrm{l}$ of HCV amplification mixture. Thermal cycler was programmed as follows: $85^{\circ} \mathrm{C}$ for $30 \mathrm{sec}, 94^{\circ} \mathrm{C}$ for 2 min followed by 40 cycles of $94^{\circ} \mathrm{C}$ for $30 \mathrm{sec}, 55^{\circ} \mathrm{C}$ for 30 sec and $72^{\circ} \mathrm{C}$ for $30 \mathrm{sec}$ and then incubation of samples for $5 \mathrm{~min}$ at $72^{\circ} \mathrm{C}$. Five $\mu l$ of first PCR product was subjected to nested PCR using nested PCR mixture containing second round primer and enzymes etc. The protocol on thermo cycler was the same as mentioned in first PCR. The PCR product was subjected to electrophoresis in $2 \%$ agarose containing ethidium bromide and was visualized under UV. A positive control provided in the kit was used as control. All positive and negative controls were tested in parallel with test samples throughout the entire procedures, starting with RNA extraction.

\subsection{Detection of $T T V$-DNA by PCR}

Viral DNA was extracted from $200 \mu$ sera stored at $-20^{\circ} \mathrm{C}$ using QiAmp Mini Elute viral spin kit (Qiagen, Germany) following manufacturer's instruction. The nucleic acid was eluted in $50 \mu$ l of elution buffer supplied with the kit. TTV-DNA (N-22) was detected by nested PCR using N-22 specific primers. Briefly, first round amplification was performed with sense primer NG059 - 5' ACA GAC AGA GGA GAA GGC AAC ATG 3' and anti-sense primer NG063 - 5' CTG GCA TTT TAC CAT TTC CAA AGT T 3' for 10 min at $95^{\circ} \mathrm{C}$ (initial denaturation) followed by 35 cycles of denaturation at $95^{\circ} \mathrm{C}$ for $30 \mathrm{sec}$, annealing at $55^{\circ} \mathrm{C}$ for $1 \mathrm{~min}$, and extension at $74^{\circ} \mathrm{C}$ for $1 \mathrm{~min}$ with final extension at $74^{\circ} \mathrm{C}$ for $5 \mathrm{~min}$. The second round of PCR was performed using sense primer NG061 - 5' GGC AAC ATG YTR TGG ATA GAC TGG 3' and anti-sense primer NG063 5' CTG GCA TTT TAC CAT TTC CAA AGT T 3' following same conditions as used for first round amplification in a thermocycler. $3 \mu \mathrm{l}$ of the PCR product were electrophoresed on $2 \%$ agarose gel and stained by ethidium bromide for the detection of 271 bp product of $\mathrm{N}-22$ region.

\subsection{Biochemical tests}

Liver function tests including transaminases levels were performed on autoanalyser Hitachi-717 by the established techniques.

\subsection{Diagnosis of viral hepatitis}

The diagnosis of different types of viral hepatitis was established as follows : The diagnosis of hepatitis A virus (HAV) infection was confirmed by the presence of IgM anti-HAV in serum. Hepatitis B virus (HBV) infection was established by finding IgM anti-HBc in sera of AVH and FHF patients and by the persistent $\mathrm{HBsAg}$ antigenemia in sera of CVH and cirrhosis cases. Similarly, total anti-HCV and IgM anti-HDV in sera samples were used for the diagnosis of HCV and recent HDV infections, respectively. Active or recent hepatitis E virus (HEV) infection was diagnosed by the presence of IgM anti- HEV in serum. Sera positive for HBsAg but negative for all other viral markers were labeled as HBV-carriers. Absence of all the markers including HBsAg labeled the patients with hepatitis non-ABCDE infection on exclusion criteria.

\section{Results}

Present report mentions the status of different types of viral hepatitis markers in sera samples from patients with various liver diseases. All the patients studied were in adult age group and belonged to both the sexes. Analysis of sera samples demonstrates that hepatitis A viral (HAV) infection is rare in adult population. IgM anti-HAV was present in 6 of 74 patients $(8.1 \%)$ with acute viral hepatitis (AVH) and none of 52 patients with fulminant hepatic failure (FHF), 102 patients with chronic viral hepatitis (CVH), 96 patients with cirrhosis and 42 patients 
with hepatocellular carcinoma (HCC). Hepatitis B infection was indicated by the presence of IgM anti-HBc in sera from AVH and FHF patients, whereas by the presence of HBsAg with or without IgM anti-HBc in sera from chronic viral hepatitis (CVH), cirrhosis of liver and hepatocellular carcinoma (HCC). Presence of IgM anti-HBc in 9 of 72 patients (12.3\%) and HBsAg in 18 of 67 patients (26.9\%) with AVH shows acute HBV infection in mere $12.3 \%$ cases with rest of population carrying HBsAg as HBV-carriers without symptoms of acute HBV infection. Similarly, IgM anti-HBc and HBsAg were noted in 11 of $53(20.8 \%)$ and 16 of $52(30.8 \%)$ cases respectively, in patients with FHF. In other disease groups, like $\mathrm{CVH}$, Cirrhosis and HCC, these two markers were recorded in different proportions as shown in Table 1 . HBV infection in these groups was found to be in $36 \%, 37.6 \%$ and $42.1 \%$ cases, respectively.

$\mathrm{HCV}$ infection in all the disease groups was detected by the presence of anti-HCV in their sera. Simultaneously, it was further confirmed by testing HCV-core antigen and HCV-RNA in sera samples. On the basis of anti-HCV in sera, HCV infection in these disease groups was demonstrated in 8 of $75(10.6 \%)$ patients with AVH, none in patients with FHF, 18 of 102 (17.6\%) patients with CVH, 25 of 69 (36.2\%) cases with cirrhosis and 8 of 19 (42.1\%) cases with HCC. However, HCV core-antigen was present in higher number of cases as compared to anti-HCV in FHF and CVH patients. In other disease groups, HCV core-antigen was recorded in lesser number of cases. Presence of HCV-RNA in relatively higher percent cases in CVH and cirrhosis points out it to be a better diagnostic marker in chronic and HCC patients. IgM-HDV infection was not recorded in all these disease groups. HEV infection, indicated by the presence of IgM-anti-HEV in sera was found in 19 of $75(25.3 \%)$ cases with AVH and 16 of 36 (44.4\%) cases with FHF, respectively. Presence of IgM-HEV was also noted in 2 of 14 $(14.3 \%)$ sera from cirrhosis of liver but none of $\mathrm{CVH}$ and $\mathrm{HCC}$ patients tested.

In order to find out the pattern of different types of infection in these disease groups (Table 2), it was noticed that HAV infection was detected in mere $8.1 \%$ cases of AVH without showing its presence in other groups. HBV infection was recorded in $12.3 \%$ cases with $\mathrm{AVH}, 20.8 \%$ cases with $\mathrm{FHF}, 36 \%$ cases with $\mathrm{CVH}, 37.6 \%$ cases with cirrhosis and $42.1 \%$ cases with HCC. Similarly, HCV infection was detected in $10.6 \%$ cases with AVH, none in FHF, $52.2 \%$ with CVH, $36.2 \%$ with cirrhosis and $42.1 \%$ with HCC. Hepatitis D infection was not seen in all these cases. HEV infection was recorded in $25.3 \%$ patients with AVH, $44.4 \%$ with FHF and $14.3 \%$ with cirrhosis. It was absent in CVH \& HCC patients. Simultaneously, TTV infection was also noted in $75.6 \%, 47.4 \%$, $53 \%, 48.4 \%$ and $66.6 \%$ cases of these groups respectively. TTV infection was also tested positive in 27 of 100 healthy persons (27\%). In each disease group, there is a population of patients carrying no known marker in their sera. It is presumed that hepatitis is caused in these patients by viruses belonging to non A-E viruses group. These viruses have to be characterized. Analysis in this patients' population has shown that non-A-E hepatitis is present in $14.5 \%$ cases with AVH, $29.6 \%$ with FHF, $19.6 \%$ with $\mathrm{CVH}, 19.8 \%$ with cirrhosis and $19.0 \%$ cases with HCC.

Table 3 demonstrates the simultaneous occurrence of different types of infections in these study groups. HBV \& $\mathrm{HCV}$ co-infection was recorded in $1.3 \%$ patients with AVH, $0 \%$ with FHF, 3.9\% with CVH, $9.4 \%$ with Cirrhosis and $7.1 \%$ with HCC cases, respectively. HCV super-infection in HBV carriers was found in $2.6 \%, 0 \%, 2.9 \%, 0 \%$ and $0 \%$ cases of these disease groups, respectively. The combined HBV, HCV and HEV infection was recorded as super-infection in $1.3 \%$ cases with $\mathrm{AVH}$ only and no other disease group. Similarly, HCV \& HEV co-infection was found in $3.9 \%$ cases with AVH only. Thus, co-infection and super-infections were not detected as common infection in these diseases groups.

\section{Discussions}

Viral hepatitis is one of the major public health problems in India. In last several years, policy makers in this country have paid special attention towards prevention and management of HIV infection. However, there was very little focus on viral hepatitis which is an equally important problem of our country. This appears the probable cause of frequent epidemics of water borne hepatitis and common occurrence of blood transmitted hepatitis reported from various set-ups with people working in high risk areas. In spite of an effective vaccine against hepatitis B to be commonly available and the basic awareness in public to prevent blood borne infections including hepatitis $\mathrm{C}$, there appears to be no substantial change in the prevalence rate and rate of incidence of viral hepatitis in different populations in this country. This leaves with no alternate than to know the exact cause of viral hepatitis and manage it with whatever therapeutic measure is available for clinical management of diseases. With this understanding, we have made further efforts to assess the etiology of viral hepatitis in different forms of liver diseases using recent viral markers and sensitive techniques.

The data of this study demonstrate the presence of all major hepatitis viruses as the causes of liver diseases in India. Hepatitis A infection, which is a common infection in children, but quite rare in adults, follows the same 
trend in this study. It was detected in very small proportion $(8.1 \%)$ of patients with AVH. In other groups, it could not show its presence. These results are in support of our previous findings (Irshad M, 1994). Hepatitis B infection was reported in more $12 \%$ cases with AVH and $20.8 \%$ cases with FHF. At the same time, it was detected in more than one third population of patients with chronic infection and hepatocellular carcinoma (HCC). As reported from several other countries (Chang MH., 2009; Wursthorn K, 2008), HBV infection appears to be one of the major causes of chronic liver diseases and liver cancer in India also. In South-east Asia, high prevalence rate of HBV infection in their populations makes it a major cause of liver cancer (Yuen MF, 2009). Exact same situation may not be here in our country as its prevalence in healthy population is relatively low. However, HBV remains as the major cause of HCC in relation to other hepatitis viruses.

$\mathrm{HCV}$ infection, another blood transmitted infection was diagnosed using three important HCV-markers, notably, anti-HCV, HCV-core Antigen and HCV-RNA. HCV-core Antigen was tested both in anti-HCV negative as well as positive cases. HCV-RNA was determined in anti-HCV positive and anti-HCV core antigen positive cases. Based on the presence of these markers, we noticed HCV infection to be present both in acute as well as chronic infections in India. It was comparatively more frequent in CVH, Cirrhosis of liver and HCC than AVH and FHF when diagnosed by anti-HCV level. HCV-core Antigen was present in high proportion of FHF as compared to anti-HCV. This needs further investigation before drawing any conclusion. If anti-HCV is taken as the criteria, $\mathrm{HCV}$ infection in AVH and FHF was noted in only $10.6 \%$ and $0 \%$ cases, respectively. Presence of HCV to be frequent in $\mathrm{CVH}$, Cirrhosis and $\mathrm{HCC}$ supports various other studies reported from different parts of the world (Reiser M, 2009; Imperial JC, 1999). HCV has been found to be one of the major cause of HCC and an important cause of mortality in South-East Asia (Kao JH, 2005; Anthony PP., 2001).

As reported earlier also, HDV infection in all these groups is absent (Irshad M, 1994). HDV infection is not very common in Indian populations. HEV infection on the contrary, has remained a major cause of several water borne epidemics in this country. In present series of patients, we found HEV infection to be the major cause of acute infection. HEV never causes chronic infection and therefore, its presence in small proportion of patients with cirrhosis may be explained mere by its occurrence and not the cause of cirrhosis. Since HEV is endemic in India and in certain areas, it is very highly prevalent; its occurrence with several other infections and in all types of population is quite common. In all sub-groups, stated percentage of cases reflects the percentage of number cases tested and not the overall population (Table-1).

In addition to the groups of already identified and characterized viruses, there are presumptive viruses causing hepatitis and accordingly they have been named as non-A-E viruses. The association of TTV infection with liver diseases as reported in several previous studies (Kanda T, 1999; Tanaka H, 1998), has forced many to explore the possibility of TTV infection causing liver diseases in India also. We studied the presence of TTV-DNA in all above cases and could find the presence of TTV infection to be substantially high in all disease groups. Simultaneously, TTV-DNA was also noted in sera from $27 \%$ healthy persons also and thus it appears to be highly prevalent in Indian populations. TTV does not prove to be the cause of liver diseases, but of course, it is frequent in Indian populations. At present we are not using TTV infection in the category of hepatitis viral infection and would conduct more studies to establish its role. On exclusion criteria, we find that there is a large population of patients in each category that do not carry any known marker but remain infected by unknown viruses grouped as non-A-E viruses. This is still a problem in India and needs extensive research to further characterize this group of viruses. In addition to this, co-infection and super-infection is also not infrequent and detected in many cases. Both co-infection and super-infection usually develop serious diseases leading to high morbidity and mortality (Sagnelli E, 2009).

\section{Acknowledgement}

The authors thank and appreciate the financial aid provided by ICMR, New Delhi, India to conduct this study.

\section{References}

Anthony PP. (2001). Hepatocellular carcinoma: an overview. Histopathology, 39(2), 109 - 118.

Bradley DW. (1992). Virology, molecular biology, and serology of hepatitis C virus. Transfus Med Rev., 6(2), $93-102$.

Chang MH. (2009). Cancer prevention by vaccination against hepatitis B. Recent Results Cancer Res., 181,85 94.

Choo, Q. L., Kuo, G., Weiner, A. J., Overby, L. R., Bradley, D. W. \& Houghton, M. (1989). Isolation of a cDNA derived from a blood-borne non-A, non-B hepatitis genome. Science, 244, 359 - 362.

Crawczynski K. (1993). Hepatitis E. Hepatology, 17, 932 - 941. 
Farci P, Gerin JL, Aragona M, Lindsey I, Crivelli O, Balestrieri A, Smedile A, Thomas HC, Rizzetto M. (1986). Diagnostic and prognostic significance of the IgM antibody to the hepatitis delta virus. JAMA, 255(11), 1443 1446.

Imperial JC. (1999). Natural history of chronic hepatitis B and C. J Gastroenterol Hepatol, 14 Suppl, S1 - S5. International Study Group on chronic hepatitis (1977). Acute and chronic hepatitis Revisited. Lancet, ii, 914 919.

Irshad M, Acharya SK. (1994). Status of Hepatitis viral markers in patients with acute and chronic liver diseases in northern India. Intervirology, 37, 369 - 372.

Irshad M, Joshi YK, Sharma Y, Dhar I. (2006). Transfusion transmitted virus (TTV): A review on its molecular characteristics and role in medicine. World J Gastroenterology, 12, 5122 - 5134.

Irshad M. (1999). Hepatitis E Virus : An update on its molecular, clinical, and epidemiological characteristics. Intervirology, 42, 252 - 262.

Kanda T, Yokosuka O, Ikeuchi T, Seta T, Kawai S, Imazeki F, Saisho H. (1999). The role of TT virus infection in acute viral hepatitis. Hepatology, 29, $1905-1908$.

Kao JH, Chen DS. (2005). Changing disease burden of hepatocellular carcinoma in the Far East and Southeast Asia. Liver Int., 25(4), 696 - 703.

Linnen J, Wages J Jr, Zhang-Keck ZY, Fry KE, Krawczynski KZ, Alter H, Koonin E, et al. (1996). Molecular cloning and disease association of hepatitis G virus: a transfusion-transmissible agent. Science, 271(5248), 505 508.

Reiser M. (2009). Viral hepatitis B and C. Med Klin (Munich), 104(5), 356 - 362.

Sagnelli E, Coppola N, Pisaturo M, Masiello A, Tonziello G, Sagnelli C, Messina V, Filippini P. (2009). HBV superinfection in $\mathrm{HCV}$ chronic carriers: a disease that is frequently severe but associated with the eradication of HCV. Hepatology, 49(4), 1090 - 1097.

Si Ahmed SN, Zoulim F. (2009). Pathobiology of HBV mutants and clinical impact for treatment monitoring. Expert Rev Anti Infect Ther., 7(3), 309 - 320.

Tanaka H, Okamoto H, Luengrojanakul P, Chainuvati T, Tsuda F, Tanaka T, Miyakawa Y, Mayumi M. (1998). Infection with an unenveloped DNA virus (TTV) associated with posttransfusion non-A to G hepatitis in hepatitis patients and healthy blood donors in Thailand. J Med Virol, 56, $234-238$.

Tandon BN, Gandhi BM, Joshi YK, Gupta H, Irshad M. (1984). Subclinical hepatitis A in north Indian children. The Lancet, 11, 335 - 336.

Tandon BN, Gupta H, Irshad M, Joshi YK, Chawla TC. (1984). Associated infection with non-A, non-virus as possible cause of liver failure in Indian HBV-carriers. The Lancet, 29, 1130 - 1131.

Tandon BN, Joshi YK, Tandon M. (1986). Acute liver failure: experience with 145 patients. J. Clin Gastroenterol, 8, 664 - 668.

Wursthorn K, Manns MP, Wedemeyer H. (2008). Natural history: the importance of viral load, liver damage and HCC. Best Pract Res Clin Gastroenterol., 22(6), 1063 - 1079.

Yang G, Vyas GN. (1996). Immunodiagnosis of viral hepatitides A to E and non-A to -E. Clin Diagn Lab Immunol., 3(3), 247 - 256.

Yuen MF, Hou JL, Chutaputti A. (2009). Hepatocellular carcinoma in the Asia pacific region. Asia Pacific Working Party on Prevention of Hepatocellular Carcinoma. J Gastroenterol Hepatol., 24(3), 346 - 353. 
Table 1. Spectrum of Hepatitis Viral Markers in Different Liver Diseases

\begin{tabular}{|c|c|c|c|c|c|c|c|c|c|c|c|c|c|c|c|}
\hline \multirow[t]{3}{*}{$\begin{array}{l}\text { Hepatitis Viral } \\
\text { Markers }\end{array}$} & \multicolumn{15}{|c|}{ Liver diseases } \\
\hline & \multicolumn{3}{|c|}{$\begin{array}{c}\text { AVH } \\
(\mathrm{n}=76)\end{array}$} & \multicolumn{3}{|c|}{$\begin{array}{c}\text { FHF } \\
(\mathrm{n}=54)\end{array}$} & \multicolumn{3}{|c|}{$\begin{array}{c}\text { CVH } \\
(\mathrm{n}=102) \\
\end{array}$} & \multicolumn{3}{|c|}{$\begin{array}{r}\text { Cirrhosis } \\
(\mathrm{n}=96)\end{array}$} & \multicolumn{3}{|c|}{$\begin{array}{c}\text { HCC } \\
(n=42)\end{array}$} \\
\hline & T.No. & +veNo. & \%age & T.No. & +veNo. & $\%$ age & T.No. & +veNo. & $\%$ age & T.No. & +veNo. & \%age & T.No. & +veNo. & $\%$ age \\
\hline IgM Anti-HAV & 74 & 6 & 8.1 & 52 & 0 & Nil & 102 & 0 & Nil & 96 & 0 & Nil & 42 & 0 & Nil \\
\hline HBsAg & 67 & 18 & 26.9 & 52 & 16 & 30.8 & 97 & 35 & 36 & 85 & 32 & 37.6 & 38 & 16 & 42.1 \\
\hline IgM Anti-HBc & 73 & 9 & 12.3 & 53 & 11 & 20.8 & 99 & 13 & 13.1 & 84 & 4 & 4.7 & 39 & 4 & 10.3 \\
\hline IgG Anti-HCV & 75 & 8 & 10.6 & 39 & 0 & Nil & 102 & 18 & 17.6 & 69 & 25 & 36.2 & 19 & 8 & 42.1 \\
\hline HCV-core Ag & 31 & 1 & 3.2 & 31 & 12 & 38.7 & 76 & 27 & 35.5 & 33 & 8 & 24.2 & 16 & 2 & 12.5 \\
\hline HCV-RNA & 2 & 0 & Nil & 12 & 0 & Nil & 23 & 12 & 52.2 & 21 & 7 & 33.3 & 5 & 0 & Nil \\
\hline IgM Anti-HDV & 18 & 0 & Nil & 16 & 0 & Nil & 35 & 0 & Nil & 32 & 0 & Nil & 38 & 0 & Nil \\
\hline IgM Anti-HEV & 75 & 19 & 25.3 & 36 & 16 & 44.4 & 25 & 0 & Nil & 14 & 2 & 14.3 & 38 & 0 & Nil \\
\hline TTV-DNA & 41 & 31 & 75.6 & 19 & 9 & 47.4 & 64 & 34 & 53.1 & 62 & 30 & 48.4 & 9 & 6 & 66.6 \\
\hline Non-A-E hepatitis & 76 & 11 & 14.5 & 54 & 16 & 29.6 & 102 & 20 & 19.6 & 96 & 19 & 19.8 & 42 & 8 & 19.0 \\
\hline
\end{tabular}

Diagnostic criteria :

$\begin{array}{lcl}\text { HBV infection } & : & \text { IgM anti-HBc in AVH \& FHF ; HBsAg / IgM anti-HBc in CVH, Cirrhosis \& HCC } \\ \text { HCV infection } & : & \text { Anti-HCV in all groups. } \\ \text { HDV infection } & : & \text { IgM anti-HDV in presence of HBsAg in all groups. } \\ \text { HEV infection } & : & \text { IgM anti-HEV in all groups. } \\ \text { TTV infection } & : & \text { TTV-DNA in all groups. } \\ \text { Non-A-E infection } & : & \text { Absence of all markers in all groups. }\end{array}$

Table 2. Different Types of Viral Hepatitis vs. Liver Diseases

\begin{tabular}{|c|c|c|c|c|c|}
\hline Type of infection & $\underline{\mathrm{AVH}}$ & $\underline{\text { FHF }}$ & $\underline{\mathrm{CVH}}$ & Cirrhosis & $\underline{\mathrm{HCC}}$ \\
\hline Hepatitis A & $8.1 \%$ & Nil & Nil & Nil & Nil \\
\hline Hepatitis B & $12.3 \%$ & $20.8 \%$ & $36 \%$ & $37.6 \%$ & $42.1 \%$ \\
\hline Hepatitis C & $10.6 \%$ & Nil & $52.2 \%$ & $36.2 \%$ & $42.1 \%$ \\
\hline Hepatitis D & Nil & Nil & Nil & Nil & Nil \\
\hline Hepatitis E & $25.3 \%$ & $44.4 \%$ & Nil & $14.3 \%$ & Nil \\
\hline TTV infection : & $75.6 \%$ & $47.4 \%$ & $53.1 \%$ & $48.4 \%$ & $66.6 \%$ \\
\hline $\begin{array}{l}\text { Hepatitis } \\
\text { non-A-E }\end{array}$ & $14.5 \%$ & $29.6 \%$ & $19.6 \%$ & $19.8 \%$ & $19.0 \%$ \\
\hline
\end{tabular}


Table 3. Status of Co- And Super-Infection in Different Liver Diseases

\begin{tabular}{|c|c|c|c|c|c|c|c|c|c|c|c|c|c|c|c|}
\hline & \multicolumn{3}{|c|}{ AVH } & \multicolumn{3}{|c|}{ FHF } & \multicolumn{3}{|c|}{ CVH } & \multicolumn{3}{|c|}{ Cirrhosis } & \multicolumn{3}{|c|}{$\mathrm{HCC}$} \\
\hline & T.No. & +veNo. & $\%$ age & T.No. & +veNo. & $\%$ age & T.No. & +veNo. & $\%$ age & T.No. & +veNo. & $\%$ age & T.No. & +veNo. & \%age \\
\hline \multicolumn{16}{|l|}{ 1. $\mathrm{HBV}$ and $\mathrm{HCV}$} \\
\hline (a) Co-inf. & 76 & 1 & 1.3 & 54 & 0 & Nil & 102 & 4 & 3.9 & 96 & 9 & 9.4 & 42 & 3 & 7.1 \\
\hline (b) Super-inf. & 76 & 2 & 2.6 & 54 & 0 & Nil & 102 & 3 & 2.9 & 96 & 0 & Nil & 42 & 0 & Nil \\
\hline \multicolumn{16}{|c|}{ 2. $\mathrm{HBV}+\mathrm{HCV}+\mathrm{HEV}$} \\
\hline (a) Co-inf. & 76 & 0 & Nil & 54 & 0 & Nil & -- & - & -- & -- & - & -- & - & - & - \\
\hline (b) Super-inf. & 76 & 1 & 13.3 & 54 & 0 & Nil & -- & - & - & -- & - & - & - & - & - \\
\hline \multicolumn{16}{|l|}{ 3. $\mathrm{HCV}+\mathrm{HEV}$} \\
\hline (a) Co-inf. & 76 & 3 & 3.9 & 54 & 0 & Nil & -- & - & - & -- & -- & -- & -- & -- & -- \\
\hline
\end{tabular}

(i) Co-infection of HBV \& HCV is indicated by presence of IgM anti-HBc \& anti-HCV in AVH \& FHF and HBsAg / IgM-anti-HBc and anti-HCV in $\mathrm{CVH}$, Cirrhosis and HCC cases.

(ii) Co-infection of HBV, HCV \& HEV is indicated by IgM-anti-HBc with anti-HCV and IgM anti-HEV in acute cases and HBsAg / IgM-anti-HBc with these markers in $\mathrm{CVH}$, Cirrhosis and $\mathrm{HCC}$ cases.

(iii) IgM-anti-HEV was not tested in $\mathrm{CVH}$, Cirrhosis and $\mathrm{HCC}$ cases.

(iv) $\%$ value was computed on the basis of total number of cases tested in each disease group.

T.No. $=$ Total number $; \quad$ +ve No. $=$ Number of sera detected positive $; \quad \%$ age $=$ Percentage of cases detected positive ; Inf. $=$ Infection. 